\title{
Engendering High Performing Employees through Business Analytics, Organisational Social Capital Building (OSCB) and Employee Engagement: A Theoretical Review
}

\author{
Bashir Aboaba Mojeed-Sanni, Ph.D
}

Assistant Professor, Business Division, Higher College of Technology, Ruwais Campus

\author{
Tasneem Tanveer Shaikh \\ Lecturer, Business Division, \\ Higher College of Technology, \\ Madinat Zayed Campus \\ Jainambu Gani Abbas \\ Lecturer, Business Division, \\ Higher College of Technology, \\ Madinat Zayed Campus
}

Doi: 10.2478/jesr-2019-0024

\begin{abstract}
Contemporary HR entails the use, and the combination of modified HR practices and functions to ensure the integration of individual trust with organizational trust leading to accumulating and harnessing employee commitment, identification, and spirit of collectivism that are necessary for the achievement of organizational outcomes. Intensified discussions about the ever-increasing role HR practitioners have to play in harnessing, the inherent, capital in human social interactions provided the stimulus and inspiration for this research paper. More so, as contemporary HR, requires the bringing forth of a highly engaged organization workforce, sustainably. This paper approaches its aim in three strands: first, the paper explores the, hitherto unknown, symbiotic relationship that exists between business analytics (BA), organisational social capital (OSC), employee engagement (EE) and high performing employees (HPE). Secondly, it examines the causal role of BA in organisations social capital building (OSCB) initiatives; the multiplier effect of OSCB on EE and consequently high performing employees. Thirdly, this paper, theoretically, identified the specific area of BA that has a direct impact on OSCB, EE, and HPE, and suggest practical implications of how BA can enhance organisation performance via OSCB and EE. The paper employs literature-based analyses, and from these conceptual, theoretical and practical arguments are established.
\end{abstract}

Keywords: HR Practice, Organisational Social Capital Building, Employee Engagement, High-Performance Employees, Business Analytics

\section{Introduction}

Employee engagement (EE) and organizational social capital (OSC) are increasingly becoming a critical issue in driving productivity and improving organisations' bottom-lines. Concurrently, by its 
mandate, organisations human resource (HR) units and practitioners are saddled with the responsibilities of linking employees to organizational strategic goals, amongst which having a highly engaged, high performing, productive, ethical, socially responsible and responsive employees take a pivotal position. The need for HR to use latent or newly generated organisation's metrics and scientific knowledge to drive and guide practical business solutions (Togt and Rasmussen, 2017); in creating a guidance system for firms cannot be over-emphasized (Chuang \& Ching-Wen, 2013: Poli, Yahya and Fee Yean, 2016). However, the role of business analytics, as well as HR use of firms metrics to facilitate EE and OSC and many other organisational outcomes, is yet to be established, at the minimum, theoretically. The ability of HR to form the foundation supporting the way an organisation's social capital is used to adequately engage employees will depend mainly on a firm's decision making culture, particularly as it relates to its most valuable resource - people. A decision-making culture where data and metrics form the fulcrum of measuring and analyzing the contribution of a particular employee towards organizational goals will result in better and more effective decisions (Frisk and Bannister, 2017).

Furthermore, Anitha (2014) and Smith \& Bititci (2017) posited that regardless of an organisation's mission statement, offerings or strategic decisions, attracting, engaging and retaining the best employees trumps all decisions. The dynamics of the business environment and evolving data has made employee engagement and performance critical to employee retention and development in contemporary organisations. Though performance appraisal is a discrete, formal, organizationally sanctioned event, usually not occurring more than once or twice a year, trust and associability - the two components of OSC can help in ensuring there is a mutual understanding on the expectation between firms stakeholders in organisations' performance management implementation process. Albrecht et, al. (2015) and Ajayi et, al (2017), establishes that employee engagement is a leadership priority even though it falls within the responsibilities of the HR department. Employees are critical assets of an organization because they contribute to its growth, thus making the need to educate, engage and empower them sacrosanct to the organisation's success.

\subsection{Research Purpose}

The aim of this paper is to establish the blurred but symbiotic relationship between business analytics (BA) (as an emerging concept in the field of business and strategic management); organizational social capital building (OSCB); EE and high performing employees (HPE). By espousing the dynamics inherent in OSCB, how it relates to EE and how BA helps organizations' maintain high performing employees through propping of both OSCB and EE.

\section{Theoretical Framework}

The theoretical framework of this study hinges on unraveling the synergetic but blurred, effect of using metrics derived within an organisation's numerous stakeholders; to measure and manage employees' performance via the conduit of OSCB and EE.

\subsection{What is in the Data? - Business Analytics - Organisational Social Capital - Employee Engagement and High Performing Employees}

Green (2017), unveiled the hidden secret of business analytics which he otherwise referred to as people analytics, and asserted that it relates to the exploration of historical data from many sources and systems. Through statistical analysis, quantitative analysis, data mining, predictive modeling and other technologies and techniques to identify trends and understand the information that can drive business change, support and sustains successful business practices. Furthermore, Green, (2016) hinted that BA or people analytics best practice is to make it the role and responsibility of chief HR officer of any organisation. On the contrary, while looking into the future of BA, van Heuvel and Bondarouk, (2017:170) concluded that "by 2025, HR analytics cum BA will become an established discipline. Have a proven impact on business outcomes, have a strong influence in 
operational and strategic decision making, characterized by integration with IT infrastructure across disciplines and even across organizational boundaries. Its function may very well be subsumed in a central analytics function - transcending individual disciplines such as marketing, finance, and HRM".

Adler and Kwon, (2002) asserted that the benefits of bridging social capital with business analytics are far-reaching and can include increased ability to gather information, ability to gain access to power or better placement within the network, or ability to recognize new opportunities. The features of organisational social capital building that draws effectiveness and productivity from an established workforce have the potential to cause negative externalities if not adequately managed. BA primarily predicts what will happen in the future, it allows for forward-projection and planning. BA combines advanced statistical analysis and predictive modeling to give an idea of what to expect so take anticipatory actions and changes now to improve outcomes (Rothberg and Erickson, 2017).

Business analytics is one aspect of business intelligence which is the sum of all research tools and information on human capital and infrastructure. It entails focusing on a statistical analysis of the information provided by business intelligence. It can also be referred to as predictive analytics which uses current and past data to let management make predictions or other unknowns. According to Pertusa-Ortega et al. (2010) and Eidizadeh et al. (2017), these sets of data can serve as predictive analytic armour and a real source of finding patterns and identifying relationships within the key data variables and providing insights as to what will happen next. These data also serve as a means of gaining competitive advantage (Ahmad, 2015). Hence, the main components of BA provide the impetus for gaining insights into specific organisation variables, particular employees, and their performance in relation to organisational goals attainment. Business analytics creates actionable plans for HR in planning and allows for immediate improvements and results by applying the insights from available metrics. Therefore, considering that organisational social capital building (OSCB) is conceptualised as the conscious and deliberate attempt and efforts by an organisation to integrate and synchronise individual trust (IT) and organisational trust (OT). To engender commitment, identification of needs and spirit of collectivism, towards the attainment of organisational outcomes (Mojeed-Sanni 2015), the role of data that present predictive opportunities becomes crucial.

Both predictive analytics and strategic organisational social capital building are crucial organizational capability and essential for quality improvement and competitive advantage. For organisations to compete favourably in today's ever-changing marketplace, it must improve on all fronts; leveraging on its unique data and dynamic resources - people. HR must ensure employees are well trained and equipped to perform in their assigned role and communicate the competence of each employee to the entire organisation. Through a regular update on training and skill-level completed by employees, briefings on completed assignments and projects by individual employees and notification of available training and skill development of all employees (MojeedSanni 2017). For organisations to apply the elements of OSCB effectively, they must consider the new approach to understanding the underlying data likely to aid and abet performance of employees in an organization. BA, a catch-all expression for approaches and technologies used to access and explore data; draw new and useful insights to improve business planning; better manage employees and identify performance and training needs. That is the use of statistical analysis and predictive modeling techniques to find underlying reasons for what has happened, why it happened and take preemptive actions. (Kapoor and Sherif, 2012) \& (Rothberg and Erickson, 2017).

For organisations to strategically use its structures (units, departments, policies, programs, and processes) to ensure its employees trust one another and are willing to go 'extra mile' and sacrifice for the organization, its decisions should be backed with sufficient data. That ensures employee needs are covered within the scope of management responsibilities. From an HR perspective, OSCB entails the use of the various HR practices to ensure the integration of individual trust with organisational trust. Leading to accumulating and harnessing commitment, identification, and spirit of collectivism necessary for the achievement of all organisational outcomes; that is, seeing OSCB as a key HR function (Mojeed-Sanni, 2015). Finding patterns and 
identifying the nature of the relationship between social networks; reciprocities and the value of achieving a mutual goal will nonetheless benefit from the hindsight of predictive data (Yu-Ping Chiu, 2015). These predictive datasets help better understanding of the complexity of distinguishing between formal and informal ties; as well as separating interpersonal trust from the interorganisational trust. According to Whelan (2016), these distinctions and understanding are crucial because both informal ties and interpersonal trust are essential for the effective functioning of organisations security networks among many other derivatives.

Furthermore, the attainment of organisation strategic objectives depends crucially on a common set of shared values and mutual trust between members of an organisation. Thus, Business Analytics + Organisational Social Capital Building + Employee Engagement $=$ Employee Performance i.e. $(B A+O S C B+E E=H P E)$. Involvement of people in the quest for quality improvement, high performance, and attainment of goals also indicates that irrespective of organisational outcome pursuits, the actual achievement of such outcomes ultimately relies on the knowledge, skills, innovation, and motivation of individuals and teams in the organization (MojeedSanni, 2017). Elana (2017) asserts that business intelligence (BI) and business analytics rely on each other. It is an error to capture data without analyzing it to help make key business decisions that will help the company move forward. Data shows what is happening within the enterprise while the $\mathrm{BI}$ process uses reporting to help spot trends that enable business decisions formulation. Firms' leaders and managers must use the combination of analytical data and mind-set adjusting initiatives, such as training, mentoring, incentives and coaching in their daily operations. They need to make data analytics fabric of daily operations. They need to include the use of metrics in their problem solving and decision-making process (Ahmad, 2015).

Barton and Court (2013), affirm that organisations not only identify and combine from multiple sources, but they should also invest in the advanced analytical models and use it to predict and optimize outcomes as well as be ready to transform their organisation so that data can yield better results for them. They further opined that ability to use data to compete and deployment of latest technology architecture for data analysis as the two competencies organisation need to possess (Boudreau and Cascio, 2017). The drivers of employee engagement such as secured status, the opportunity for learning, career progression, promotion, compensation, adequate infrastructure, amongst others ought to be planned for based on observations provided by business analytics.

To this end, HR is concerned about maximising the benefits of an organisation's employees, by developing their capacity in line with set objectives (goals), which occurs through strategic engagement, to knowing the required training and motivational programmes that will assist management in performing continuous appraisals based on established goals. Organisations should develop a social capital framework within available statistical data to achieve sustainable engagement with the employees. The purpose is to ensure the set goals of the organization gets the buy-in of everyone. HR executives must recognize the need to develop an integrated approach aimed at boosting the confidence of the employee and developing trust to walk in the light of the vision and mission of the organization. In reality, it is the summation of social ties, level of personal and organisational trust and employees commitment that is the most effective way to drive performance management. When pursued intelligently in conjunction with the use of reliable and verifiable data and information, these concepts - BA, OSC, and EE are more than capable of helping organisations to constructively manage, attract, and retain employees (Smith and Bititci, 2017). Indeed, most employees seek organisations that can provide them with opportunities to strengthen social ties within and outside their work enclosures; that allows them to ventilate ideas; grow and provide them with enough support to take initiatives, discretionary.

The process of engaging employee to achieve the goals of an organisation efficiently, safe and mutually beneficial manner can only be attained when the collection of empirical data has given management head-start to be able to know the organisational social capital building technique to deploy. OSCB traverses corporate frontiers; it allows for divergent opinion, tolerance, and acceptance of different people, values, and beliefs through contact with diverse stakeholders thus building trust. It takes business analytics to aggregate essential data for informed decision-making that will drive business impact. Decision makers do not want voluminous or raw data; they needed aggregated reports that indicate trends, challenges, and opportunities. That is precisely what 
business analytics provides in the circle of using OSCB and EE to drive high performance. Figure 1 depicts the causal relationship between these concepts.

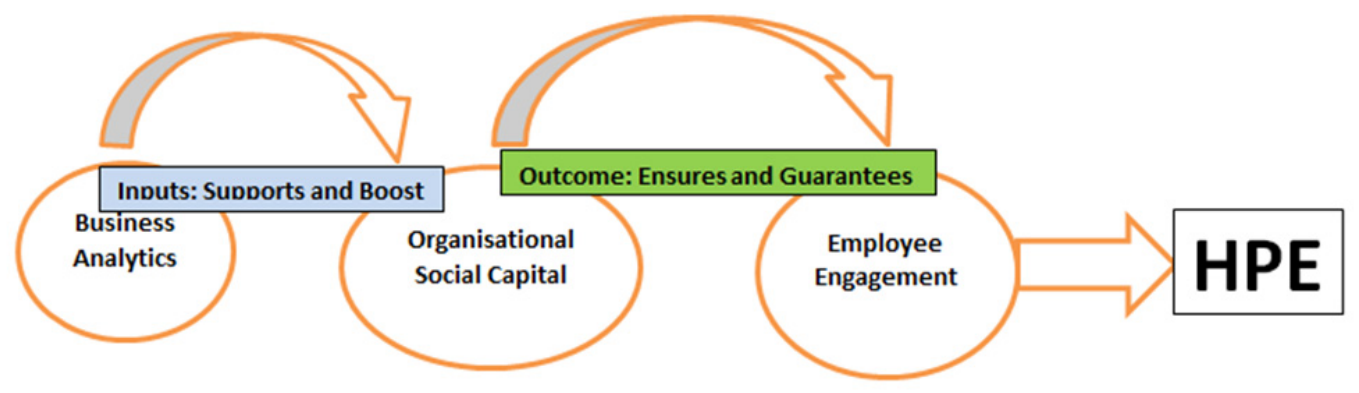

Fig. 1. Causal Relationship of BA, OSC, EE and HPE

According to Van Burren (2008), Greenwood and Van Buren III (2010), Chamanifard et al., (2015) and Ajonbadi \& Mojeed-Sanni (2015), associability emphasise the importance of willingness of an employee to subordinate his or her individual goals and aspirations for the collective and organisational goals. However, it coincidentally mirrors the positions of Guest (2014), Anitha (2014), Taneja, et al., (2015) and Kim and Gatling (2018) on employee engagement. These authors postulate that EE entails the extent at which employees are not only passionate and committed to their job and organisation, they hinged and differentiate EE from employee satisfaction or job satisfaction with a willingness to exert discretionary efforts. Furthermore, trust another major component of OSC relates to dyadic trust, personal trust and organisational trust that exists in an organisation. That is, the ability of employees to subject themselves to the vulnerability of the actions and inactions of their team members or co-worker without taking precautionary actions (Li et al., 2016) and (Agyapong et al., 2017) which in turn breeds confidence and elicits positive employee-employer relationship. The summation of these concepts, ideas, and traits do not only lead to having a high performing workforce; they require strategic, bespoke and purposely sourced data and metrics provided by BA.

\subsection{Configuring Organisational Social Capital, Employee Engagement for High Performance}

The act of building interpersonal and social networks amongst employees is crucial to the survival of an organization. Organisations and workplaces are an avenue for building a sustainable network with the potential to influence both personal and collective output. The engagement that occurs amongst employees and management is one of the key ingredients for achieving high performance. Research has shown that highly engaged employees in one organization perform $20 \%$ better than those with average engagement in another (Mann and Harter, 2016).

By creating the avenue for interpersonal development, organisations improve their social capital and indeed business bottom-line. When employees are engaged, there is an element of full disclosure where full knowledge of strategic plans of the organisation draws commitment and willingness to carry out discretional efforts from the organization by employees. Kruse (2015) defines employee engagement as the emotional commitment that employees have to their organization and the organization's goals. According to Anitha (2014), organisations that consciously implement policies and process geared towards formalising engagements are, more likely than not, to witness improved profit generation, reduce cost, eradicate disputes and conflict of interest and roles and achieve sustainable growth. It is instructive to note, according to Kruse (2015), that employee engagement does not mean employee satisfaction. Even though many organisations flaunt their yearly "employee satisfaction" survey, they forget the distinctive element in EE - the willingness to go the "extra mile," something that is akin to the willingness to subordinate individuals goals for the collectives (Greenwood and Van Buren, 2010). 
Engaged employees enhance productivity and business outcomes. According to Kruse (2015), in pursuit of high customer satisfaction, firms and managers aim for high service quality and productivity and consequently increases profit and other organisation bottom-lines. However, these organisation outcomes are possible only in a climate of positivity and enthusiasm, guaranteed through OSCB and EE (Anitha, 2014) and (Taneja, Sewell and Odom, 2015). While analysing existing research on employee engagement, Kruse (2015) narrowed the process to engaging employees to five basic elements which are also crucial to OSCB; trust, social relations, commitment, communication, and influence. Social capital influences an employee's sense of belonging by instigating feelings of trust and safety amongst employees. Social capital is seen as the cooperative relationships between social actors that facilitate collective action. When there is a broad social capital building, it creates unbridled access to the resources employees need for survival and progression at work. Helliwell and Putnam, (2004) put forward the notion that social capital exists and develops in the relations among people as actors, and those relationships can either be within an organisation (bonding capital) or externally (bridging capital). These internalexternal capitals develop relationships important to an organisation's viability and develop beneficial partnerships supporting ongoing business and community exchanges, enabling sustainable, longterm programs to become part of business and community engagement.

When viewed from organisational HR perspectives, OSCB entails the use of, the various, HR practices and functions to ensure the integration of individual trust with organisational trust leading to accumulating and harnessing employee commitment. The key indicators of OSCB and critical $\mathrm{HR}$ responsibilities aimed at engaging employees and driving performance in an organisation are listed as: (1) encouraging effective and affective social interactions at work, (2) ensuring existence of personal/dyadic trust amongst employees, (3) encouraging friendship relationships among employees, (4) ensuring employees' commitment to organisation's mission and vision, (5) ensuring employees' identification with the organisation's purpose, (6) ensuring, and encouraging helping behaviours at work and (7) encouraging cooperation and knowledge-sharing among employees (Mojeed-Sanni, 2015).

Figure 2 shows the dynamics of BA, OSCB, EE, and HPE. OSCB indicators and initiatives will benefit from metrics garnered through $B A$, which will consequently ensure employees will have opportunities for advancement because there will be an alignment of purpose, goals, strategy, capacity, and belief which are the first key to maximizing engagement (Shuck and Herd 2012). Organisational social capital building allows different primary stakeholders to share and exchange information, innovative ideas and builds consensus among the groups representing diverse interests with the aim of attaining set goals. Employee engagement emphasizes goal-setting and meeting those goals because employees attainment of set performance goals and targets is the pillar around which organisations continuous growth and success revolve. Hence, it is pertinent that there is a deliberate attempt on the part of the leadership of an organisation to engage the employee by showing concern for their plight and building trust as a means of maintaining the operational standard of the organisation. 


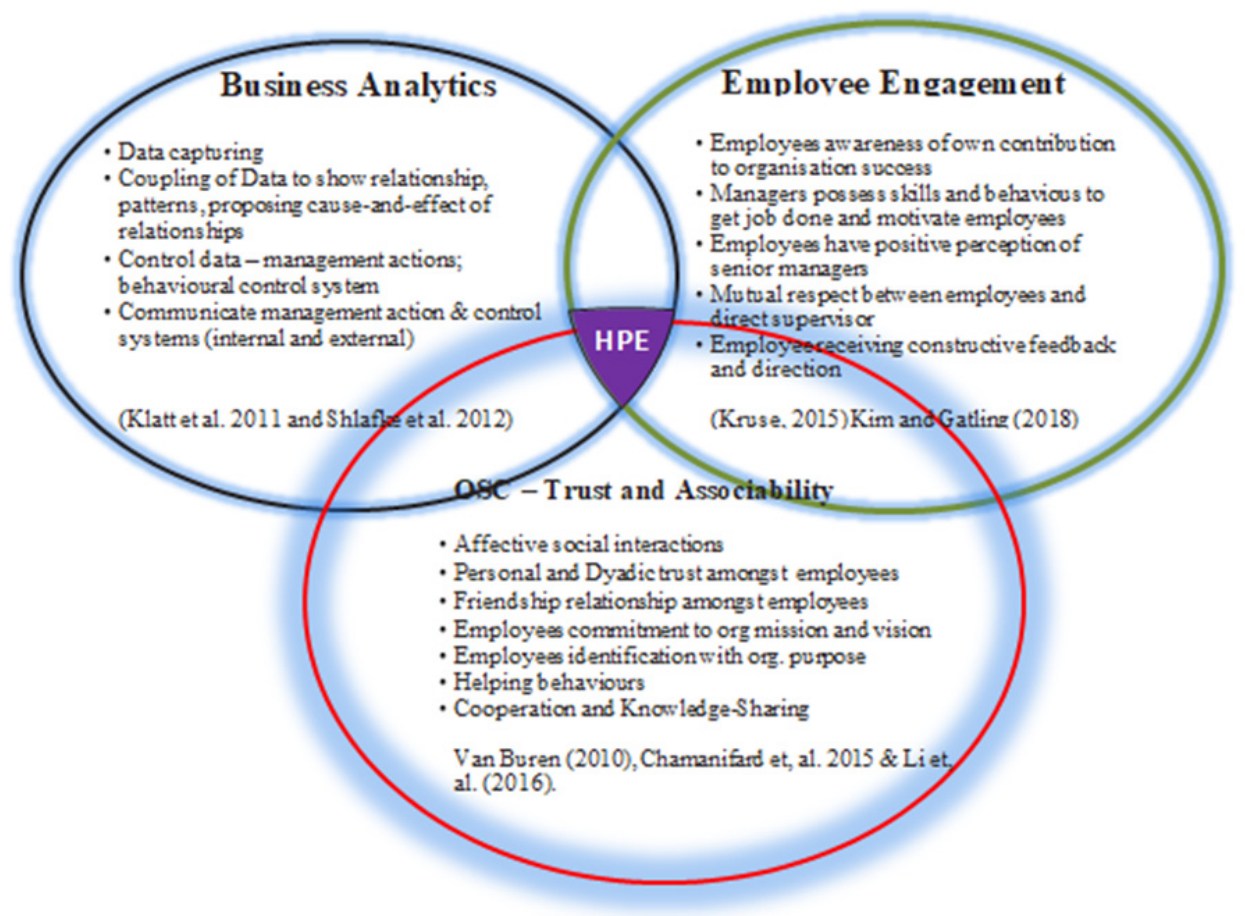

Fig. 2. Dynamics of BA, OSC, EE and HPE

\section{Discussion and Practical implications}

Organisations need to strategically configure their BA initiatives to retrieve specific metrics capable of building OSC; drive employee engagement and subsequently lead to attracting, maintaining and sustaining high performing employees. More effective application of BA analytics should lead to harnessing social capital inherent in an organisation and bring forth committed and passionate workforce that is capable of raising the bar of their performance.

Contemporary firms, desirous of sustainable growth and development need not look far, what is needed growth and development are hidden in the support and role of business analytics in the process of harnessing the capital inherent in human social interactions between and amongst employees in their firms. Harnessing the value of social interaction between actors and stakeholders present an organisation with a unique, rare and inimitable resource and competitive advantage. Since most managers firmly believe the significance of their firm's growth is attributable to their own or their employee's relationships with other actors inside and outside the company. Such relationships as opined by Bamiatzi and Sinkovics (2010) help in promoting the name of the company, attracting new potential clients, receiving quick and valid information about the market and or new possible products/service. It also helps in getting advice and consultation, especially in stressful situations, to develop employee knowledge towards the social capital building of the organisation.

Exploiting generative data about the sort of relationship between the key stakeholders in an organisation helps in strategic policy formulation, mainly as HR practices in the 21st century requires strategic flexibility that has been proven to have a positive and profound impact on employee productivity (Xiu et al., 2017). Contemporary HR practice could benefit from business analytics in the form of HR analytics and use data generated from adventures such as 360-degree 
surveys, and virtual focus groups would help organisations clarify objectives and ensure that team discussions are action-oriented (Briggs, 2011). A 360-degree survey data or virtual focus group data will help an organisation determine which items are impacting on social capital building indicators aforementioned in this paper and on overall engagement within each demographic groups. The same data can then be used to track performance improvement; monitor progress and provide fact-based input to appraisals and ensure high performing employees. Figure 3 depicts how organisations can configure BA for OSCB, EE, and HPE.

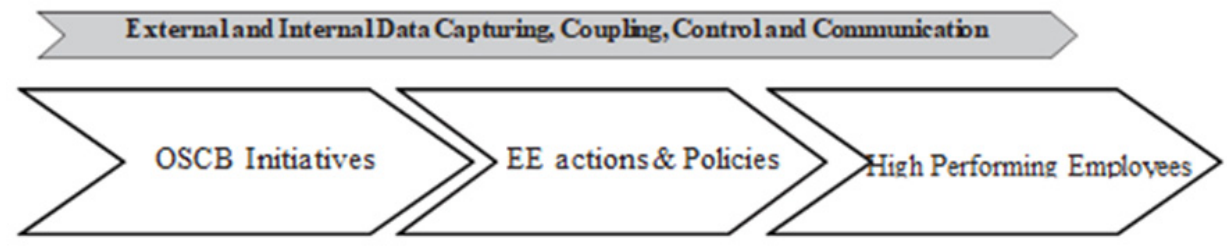

Figure 3. Configuring Business Analytics for OSCB, EE, and HPE

More recently, Brockbank et al. (2018) argued the case for HR to be actively involved in the leveraging information and statistical data available within and outside their organisations. They contend that HR should tip-the-scale of information management within their organisation and use their involvement to not only to identify crucial external information, such as customers' information, suppliers and strategic partners' information and competitive information. Through their involvement they should import crucial external information into their firm and use that to add value to their stakeholders; use it to improve HR and other functional processes and practices; create competitive advantage through organization-wide employee and employment relations capability. In other words, organisations HR should use data generated through and from business analytics to build organisation social capital, drive employee engagement and provide veritable high performing employees for their firm in the process.

\section{Design/Methodology/Approach}

The approach adopted for this paper follows deductive reasoning based on the relativist interpretivism paradigm. According to Saunders et al. (2009), a deductive approach entails that the research starts from already existing theories and models, from which propositions are not only developed, a different point of views compared and contrasted while adding owns views. Hence, this paper employs a literature-based analysis, and from this, theoretical postulations were explored. It started by exploring and espousing existing concepts and ideas: organisation social capital, employee engagement, high performing employee and business analytics. It then established the causal relationship between these concepts and concluded on what organisations need to do to benefit from their symbiotic relationship.

\subsection{Research Limitations and Suggestion for Further Study}

The fact that this is a pure theoretical review of existing literature on HR and organisation behaviour related concepts is enough limitation on its own. As the purported symbiotic relationship that exists among these concepts is yet to be empirically tested from either the perspectives of HR practitioners or the numerous stakeholders in an organisation or perhaps from organisation/industry/discipline and country/culture/climate perspective. Also, this paper did not cover the specificity of BA data needed for OSCB and EE. Organisations, practitioners, and scholars will benefit more from in-depth research that explores the specific type of data that organisations need to generate to ensure that their OSCB initiatives are compelling enough to drive employee engagement and performance. 


\section{Conclusion}

Today, most organisations operate in a dynamic and turbulent business environment where their human capital would need to present and demonstrate further characteristics, such as good communication skills, tolerant for others behaviour, empathy with others, commitment, respect and ability to socially interact with others to achieve competitive advantage. Hence, it is pertinent for firms to use the potential and emerging information derivable from within and outside the company to find patterns of relationship that exists between its stakeholders. Furthermore, given that the social environment of an employee contributes significantly to their attitude to work, final output, their willingness to exercise discretionary efforts, their commitment and passion for their job. It is crucial that organisations strategically capture (retrieve latent and consciously source new metrics), couple (make meanings out of available data), control (provide policy guidelines based on available data) and communicate (internal and externally) rare, unique and specific data that will contribute to instituting a business environment that breeds high performing employees.

\section{References}

Adler, P. S. \& Kwon, S. (2002). 'Social Capital: Prospects for a new concept.' Academy of Management Journal, 27 (1), $17-40$.

Aguinis, H. (2011). Performance Management. 2nd Edition. Upper Saddle River, NJ: Person Prentice Hall.

Agyapong, F. O., Agyapong, A., \& Poku, K. (2017). 'Nexus between social capital and performance of micro and small firms in an emerging economy: The mediating role of innovation.' Cogent Business \& Management, 4(1), 1309784.

Ahmad, A. (2015). Business intelligence for sustainable competitive advantage. In Sustaining Competitive Advantage via Business Intelligence, Knowledge Management, and System Dynamics (pp. 3-220). Emerald Group Publishing Limited.

Ajayi, O. M., Odusanya, K., \& Morton, S. (2017). 'Stimulating employee ambidexterity and employee engagement in SMEs.' Management Decision, 55(4), 662-680.

Ajonbadi, H. A, Mojeed-Sanni, B. A \& Otokiti, B. O. (2015). 'Sustaining Competitive Advantage in Medium-sized Enterprises (MEs) through Employee Social Interaction and Helping Behaviours.' Journal of Small Business and Entrepreneurship Development, 3(2). Pp.89-112

Ajonbadi, H.A. \& Mojeed-Sanni, B.A. (2015). 'Strategic Social Capital Building in the Nigerian Medium-sized Enterprises (MEs): The Impact of Industry Specialization.' Academic Journal of Interdisciplinary Studies, 4(3). Pp.142-165

Al Arkoubi, K. \& Elizabeth, D. (2013). Building Sustainable Organizational Social Capital: The Global Leadership Challenge. Global Journal of Management and Business Research Administration and Management. Volume 13 Issue 9 Version 1.0.

Albrecht, S. L., Bakker, A. B., Gruman, J. A., Macey, W. H., \& Saks, A. M. (2015). 'Employee engagement, human resource management practices and competitive advantage: An integrated approach.' Journal of Organizational Effectiveness: People and Performance, 2(1), 7-35.

Anitha J. (2014)."Determinants of employee engagement and their impact on employee performance", International Journal of Productivity and Performance Management, Vol. 63 Issue: 3, pp.308-323

Bamiatzi, V. C., \& Sinkovics, R. R. (2010). The Role of Human and Social Capital Traits in SMEs OverPerformance during Industrial Downturns: Theoretical Development.

Barton, D. \& Court. D. (2013).Three keys to building a data-driven strategy, Retrieved April 16, 2017, from https://www.mckinsey.com

Bartram, D. (2005). "The great eight competencies: a criterion-centric approach to validation," Journal of Applied Psychology, Vol. 90 No. 6, pp. 1185-1203

Boselie, P. (2010). 'High-performance work practices in the healthcare sector: a Dutch case study.' International journal of manpower, 31(1), 42-58.

Boudreau, J., \& Cascio, W. (2017). 'Human capital analytics: why are we not there?'. Journal of Organizational Effectiveness: People and Performance, 4(2), 119-126.

Briggs, H. (2011). 'How to use a data-focused approach to embed good HR practices.' Strategic HR Review, 10(2), 18-23.

Brockbank, W., Ulrich, D., Kryscynski, D., \& Ulrich, M. (2017). 'The future of HR and information capability.' Strategic HR Review, Vol. 17 Issue: 1, pp.3-10 
Chamanifard, R. A. H. E. L. E. H., Nikpour, A. M. I. N., \& Chamanifard, S. H. E. I. D. A. (2015). 'The Effect of Social Capital on Organizational Performance: The Mediating Role of Employee's Job Satisfaction.' International Review of Management and Business Research, 4(3), 853-860.

Chuang, C. H., Chen, S. J., \& Chuang, C. W. (2013). 'Human resource management practices and organizational social capital: The role of industrial characteristics.' Journal of Business Research, 66(5), 678-687.

Čirjevskis, A. (2017). "Unbundling dynamic capabilities in successful Asian-Pacific shipping companies", Journal of Asia Business Studies, Vol. 11 Issue: 2, pp.113-134,

De Waal, A.A \& Oudshoorn, M. (2015) "Two profiles of the Dutch high performing employee", European Journal of Training and Development, Vol. 39 Issue: 7, pp.570-585

Deepak Agrawal, D. (2014). "Analytics based decision making". Journal of Indian Business Research, Vol. 6 Issue: 4, pp.332-340,

Eidizadeh, R., Salehzadeh, R., \& Chitsaz Esfahani, A. (2017). 'Analysing the role of business intelligence, knowledge sharing and organisational innovation on gaining competitive advantage.' Journal of Workplace Learning, 29(4), 250-267.

Frisk, J. E., \& Bannister, F. (2017). 'Improving the use of analytics and big data by changing the decisionmaking culture: A design approach.' Management Decision, 55(10), 2074-2088.

Green, D. (2017)."The best practices to excel at people analytics." Journal of Organizational Effectiveness: People and Performance, Vol. 4 Issue: 2, pp.137-144

Greenwood, M., \& Van Buren III, H. J. (2010). 'Trust and stakeholder theory: Trustworthiness in the organisation-stakeholder relationship.' Journal of business ethics, 95(3), 425-438.

Griffith, D. A \& Harvey, M.G. (2004). 'The influence of individual and firm-level social capital of marketing managers in a firm's global network.' Journal of World Business, 39(3), 244-254.

Guest, D. (2014)."Employee engagement: a sceptical analysis." Journal of Organizational Effectiveness: People and Performance, Vol. 1 Issue: 2, pp.141-156,

Helliwell, J. F., \& Putnam, R. D. (2004). 'The social context of well-being.' Philosophical Transactions of the Royal Society B: Biological Sciences, 359(1449), 1435.

Kapoor, B., \& Sherif, J. (2012). 'Human resources in an enriched environment of business intelligence.' Kybernetes, 41(10), 1625-1637.

Kim, J., \& Gatling, A. (2017). 'The impact of using a virtual employee engagement platform (VEEP) on employee engagement and intention to stay.' International Journal of Contemporary Hospitality Management, Vol. 30 Issue: 1, pp.242-259

Klatt, T., Schlaefke, M., \& Moeller, K. (2011). 'Integrating business analytics into strategic planning for better performance.' Journal of business strategy, 32(6), 30-39.

Kruse, K. (2015). 'The ROI of Employee Engagement in Hospitals.' Forbes/Leadership.

Levenson, A. \& Fink, A. (2017). "Human capital analytics: too much data and analysis, not enough models and business insights", Journal of Organizational Effectiveness: People and Performance, Vol. 4 Issue: 2, pp.145-156,

Li, C. P., Yahya, K. K., \& Yean, T. F. (2016). 'Organizational Social Capital and Commitment-Based HR Practices as the Determining Factors of Organizational Performance.' International Journal of Business and Management, 11(6), 129.

Luarn, P., \& Chiu, Y. P. (2015). 'Key variables to predict tie strength on social network sites.' Internet Research, 25(2), 218-238.

Mann, A., \& Harter, J. (2016). 'The worldwide employee engagement crisis.' Gallup Business Journal, 7.

Mojeed-Sanni, B. (2015). Attitudes of HR Practitioners to Organizational Social Capital Building (OSCB): The Study of Nigerian Medium-Sized Enterprises (MEs) HR Practitioners. (unpublished A Thesis Submitted for the Degree of Doctor of Philosophy, University of Wales, Cardiff)

Mojeed-Sanni, B. A. (2017). 'Total Quality management and Organisational Social Capital Building: Two of a Kind?' International Journal of Research in Economics and Social Sciences (IJRESS), Vol. 7 Issue 5, May- 2017 Pg. 369-370

Peng, Y. P., \& Lin, K. H. (2017). 'The effect of global dynamic capabilities on internationalizing SMEs performance: Organizational culture factors as antecedents.' Baltic Journal of Management, 12(3), 307328.

Pertusa-Ortega, E. M., Molina-Azorín, J. F., \& Claver-Cortés, E. (2010). 'Competitive strategy, structure and firm performance: A comparison of the resource-based view and the contingency approach.' Management Decision, 48(8), 1282-1303.

Rothberg, H. N., \& Erickson, G. S. (2017). 'Big data systems: knowledge transfer or intelligence insights?' Journal of Knowledge Management, 21(1), 92-112.

Saunders, M. N. (2011). Research methods for business students, 5/e. Pearson Education India.

Schläfke, M., Silvi, R., \& Möller, K. (2012). 'A framework for business analytics in performance management.' International Journal of Productivity and Performance Management, 62(1), 110-122. 
Shuck, B., \& Herd, A. M. (2012). 'Employee engagement and leadership: Exploring the convergence of two frameworks and implications for leadership development in HRD.' Human resource development review, 11(2), 156-181.

Smith, M., \& Bititci, U. S. (2017). 'Interplay between performance measurement and management, employee engagement and performance.' International Journal of Operations \& Production Management, 37(9), 1207-1228.

Taneja, S., Sewell, S. S., \& Odom, R. Y. (2015). 'A culture of employee engagement: A strategic perspective for global managers.' Journal of Business Strategy, 36(3), 46-56.

Van Buren, H. J. (2008). 'Building Relational Wealth in the New Economy: How can Firms Leverage the Value of Organisational Social Capital.' International Journal of Management, 25(4), 684-690.

Van den Heuvel, S., \& Bondarouk, T. (2017). 'The rise (and fall?) of HR analytics: A study into the future application, value, structure, and system support'. Journal of Organizational Effectiveness: People and Performance, 4(2), 157-178.

Van der Togt, J., and Rasmussen, T.H. (2017), "Toward evidence-based HR," Journal of Organizational Effectiveness: People and Performance, Vol. 4 No. 2, pp. 149-154

Vlachos, I. P. (2009). 'High-performance workplace practices for Greek companies.' EuroMed Journal of Business, 4(1), 21-39.

Whelan, C. (2016). "Informal social networks within and between organisations: On the properties of interpersonal ties and trust". Policing: An International Journal, Vol. 39 Issue: 1, pp.145-158,

Xiu, L., Liang, X., Chen, Z., \& Xu, W. (2017). Strategic flexibility, innovative HR practices, and firm performance: A moderated mediation model. Personnel Review, 46(7), 1335-1357. 